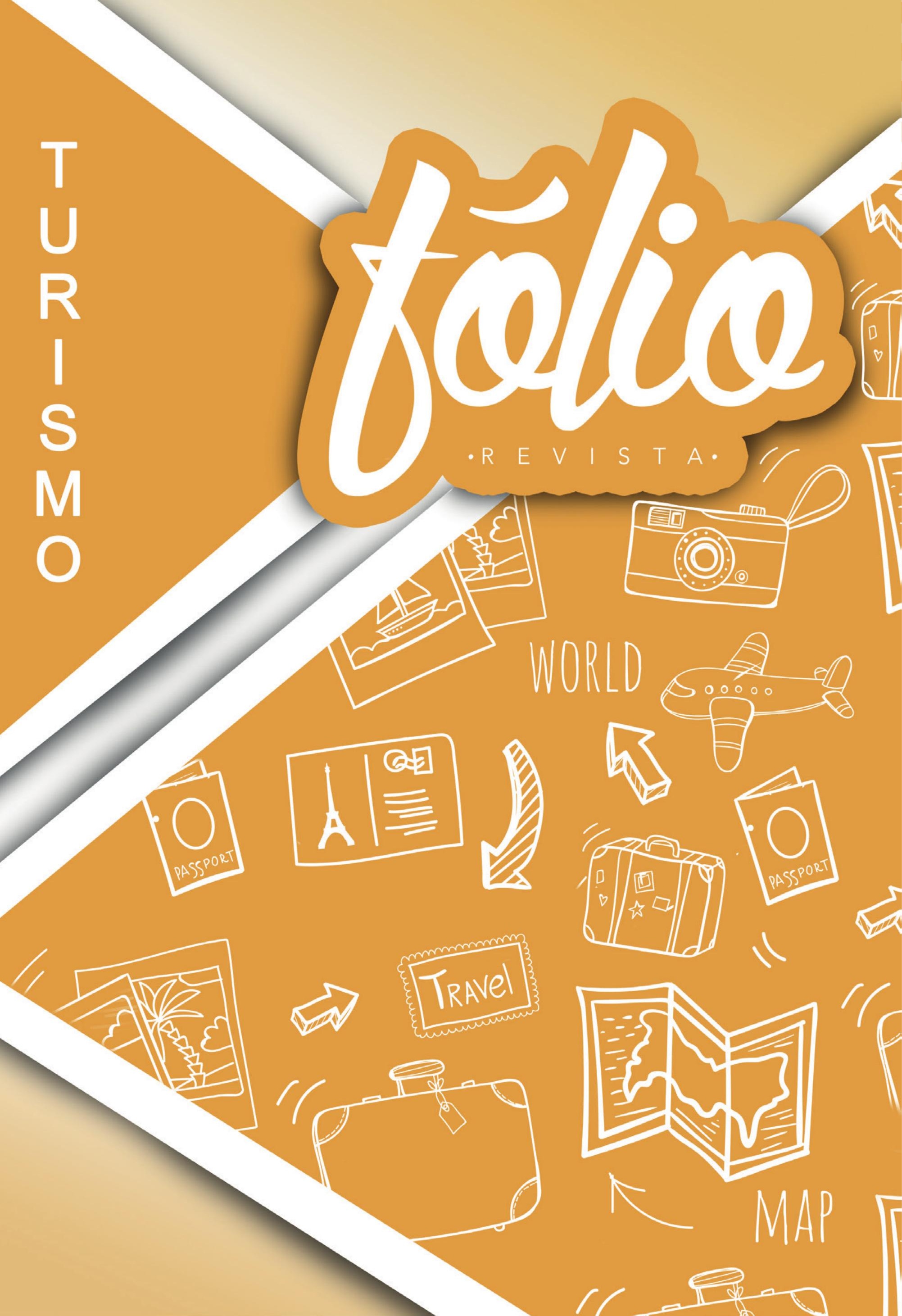




\title{
O museu do pão e os caminhos dos moinhos: sobre a cultura e turismo no desenvolvimento de territórios
}

\author{
Maximilianus Andrey Pontes Pinent ${ }^{1}$ \\ Luciane Scherer ${ }^{2}$
}

\section{Resumo}

O presente artigo traz uma reflexão sobre cultura e turismo, e a importância de fenômenos como turismo cultural na valorização do patrimônio material e imaterial no desenvolvimento de um território. $\bigcirc$ estudo situa-se na Região do Vale do Taquari, no Rio Grande do Sul, onde situa-se o Museu do Pão, atrativo cultural na qual a presente análise está focada e da qual surge a proposta do roteiro turístico Caminho dos Moinhos. A presente pesquisa é pautada tanto por esforços epistemológicos (com revisão bibliográfica sistemática e análise documental) como ontológicos (com a observação participante). Compreende-se que a cultura e a patrimônio, apresentadas por meio do turismo, requerem planejamento e acompanhamento a fim de se maximizar os benefícios culturais, sociais e econômicos para a região, a fim de fortalecer toda a cadeia do turismo da região. Como resultados, além da análise do atrativo apresentam-se alguns indicadores de sustentabilidade a serem trabalhados para a manutenção econômica que alicercem objetivos sociais da entidade responsável pelo Museu do Pão e pelo roteiro Caminho dos Moinhos.

Palavras-chave: Turismo Cultural. Museu do Pão. Caminho dos Moinhos.

\section{Resumen}

El presente artículo trae una reflexión sobre cultura y turismo, y la importancia de fenómenos como turismo cultural en la valorización del patrimonio material e inmaterial en el desarrollo de un território. El estudio se sitúa en la Región del Valle del Taquari, en Rio Grande do Sul, donde se sitúa el Museo del Pan, atractivo cultural en el que está presente el presente análisis y de la que surge la propuesta del itinerario turístico Camino de los Molinos. La presente investigación es pautada tanto por esfuerzos epistemológicos (con revisión bibliográfica sistemática y análisis documental) como ontológicos (con la observación participante). Se entiende que la cultura y el patrimonio, presentados por medio del turismo, requieren planificación y acompañamiento a fin de maximizar los beneficios culturales, sociales y económicos para la región, a fin de fortalecer toda la cadena del turismo de la región. Como resultados, además del análisis del atractivo se presentan algunos indicadores de sostenibilidad a ser trabajados para el mantenimiento económico que alicen los objetivos sociales de la entidad responsable del Museo del Pan y del itinerario Camino de los Molinos.

Palabras clave: Turismo Cultural. Museo del Pan. Camino de los Molinos.

\footnotetext{
1 Bacharel em Turismo (PUCRS). Mestre em Desenvolvimento Regional. Docente dos Cursos de Turismo da FACCAT e da UNISC. maximilianus@pinent.com.br
}

2 Administradora (UFRGS) e Bacharel em Turismo (PUCRS). Docente do curso de Administração da URI. lucianascherer@yahoo.com.br 


\section{Introdução}

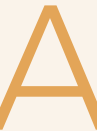

compreensão da importância do patrimônio cultural para o desenvolvimento do turismo é cena corriqueira para a gestão pública em qualquer cidade do mundo. A importância socioeconômica também atrai inúmeras empresas, entidades e indivíduos para o investimento de recursos e ou tempo para colaborar na preservação histórico-cultural de bens materiais e imateriais que contem para as gerações futuras a intervenção humana na formação de comunidades, com suas tradições, costumes e relevâncias.

Para demonstrar a relevância da cultura e do turismo como instrumento da preservação cultural, neste artigo propõe-se uma reflexão entre fenômenos socioculturais e econômicos que permeiam a sociedade: a contextualização da preservação cultural pela história contada do pão e sua influência para a geração do fluxo de visitantes no pequeno município de llópolis, no Vale do Taquari, no Rio Grande do Sul. O argumento central baseia-se no turismo como propulsor de desenvolvimento regional, influenciando os municípios lindeiros à constituição do Caminho dos Moinhos focado na preservação de bens materiais e imateriais que mesclam a história do pão e da colonização italiana no Rio Grande do Sul.

A importância do trabalhou pauta-se no posicionamento de que Turismo contribui para o desenvolvimento sociocultural das populações, por aliar à manutenção de características sociais a atração de novos olhares para o encantamento do (re)conhecimento de recursos naturais e culturais na formação dos territórios, como a preservação de bens culturais, tradições e costumes.

O estudo de caso é o Museu do Pão, que tem como território de análise Ilópolis, no Vale do Taquari, no Estado do Rio Grande do Sul, na qual situa-se uma significativa riqueza histórica e cultural do Brasil: o território da colonização italiana, cujos imigrantes estabeleceram suas propriedades na produção de farinha de trigo.

O Museu do Pão, precede a constituição de um roteiro turístico de abrangência regional, o Caminho dos Moinhos, baseado em cultura, na preservação do patrimônio e da historicidade, e que integra a região em termos geográficos, eco- nômicos, e socioculturais por meio da interação entre os turistas e moradores.

Objetivo do trabalho é caracterizar e analisar o Museu do Pão, bem como apresentar o Caminho dos Moinhos, refletindo sobre suas contribuições para o turismo e a cultura no município de Ilópolis, RS e da Região do Vale do Taquari. A presente pesquisa é pautada por esforços epistemológicos, com revisão bibliográfica e analise documental; e ontológicos, com observação participante.

trabalho está dividido em 4 partes, além dessa introdução e das considerações finais: a primeira apresenta os pressupostos metodológicos que nortearam a construção desse estudo. A segunda discute aspectos sobre cultura, turismo e o turismo cultural tratando de suas relações e suas potencialidades para o desenvolvimento de territórios. Na sequência, procura-se apresentar o Museu do Pão e analisar, mediante pesquisas documentais e observação participante, o seu papel na ressignificação da cultura e da memória, e no desenvolvimento da região. Por último, apresenta-se a proposta de roteiro turístico "Caminho dos Moinhos", que percorre outros 3 moinhos nos municípios do Vale do Taquari: Anta Gorda, Arvorezinha e Putinga.

A emergência da experiência da colonização italiana em solo rio-grandense se mostra plena de questões sociais, culturais e econômicas. Neste sentido, além de registrar a trajetória histórica que incluiu brasileiros e imigrantes italianos em uma construção identitária estrategicamente valorizadacomo fator de atração turística no Estado, remete à reflexão sobre as estratégias de constituição de "templos" da preservação cultural em museus interativos como o Museu do Pão, que incitam o olhar e o aprender-fazer para a preservação de costumes que contribuíram para o desenvolvimento das sociedades.

\section{Metodologia de pesquisa}

A presente pesquisa é pautada tanto por esforços epistemológicos como ontológicos. Para atender as questões epistemológicas as técnicas utilizadas foram a revisão bibliográfica sistemáti- 
ca e a análise documental, a partir de análises de referencial teórico sobre cultura, patrimônio material e imaterial e turismo. Para as questões ontológicas a técnica utilizada foi a observação participante com visitas in loco no Museu do Pão e no Roteiro Caminho dos Moinhos.

A revisão bibliográfica sistemática foi utilizada como forma de obter evidências (PEARSONS apud BOTELHO el al, 2011) para demonstrar o quão relevante é a cultura e a valorização patrimonial para o turismo e vice-versa. Para tanto, identificou-se em 23 artigos selecionados de revistas científicas que dedicam suas publicações ao tema cultura que correlacionam intrinsecamente o turismo como vetor de promoção dos interesses da educação social e da preservação de acervos de cultura material e imaterial: Revista Confluências Culturais; Gest e Prod; TuryDes - Revista de investigación em turismo y desarrollo local; PASOS- Revista de Turismo y Patrimonio Cultural e RITUR- Revista Iberoamericana de Turismo. O critério para seleção desses artigos foi baseado em sua importância para a produção cientifica do turismo. A partir da utilização dessa técnica foi possível evidenciar a aproximação entre os saberes da cultura e do turismo como oferta de produtos de viagem e turismo.

A segunda técnica utilizada nesse estudo, a análise documental é aquela cuja realização está vinculada aos objetos de investigação escolhidos pelos pesquisadores que as integram (CORSETI, 2006), sendo os principais acervos utilizados documentos legais, os documentos da construção do Museu do Pão (BRASIL ARQUITETURA, 2008) e do projeto Caminho dos Moinhos (TOUGUINHA, SD; CAMINHO DOS MOINHOS, 2017; PREFEITURA MUNICIPAL DE ILÓPOLIS, 2017).

E a terceira técnica utilizada, a observação participante, é considerada nesse contexto como um método no qual o investigador participa nas atividades diárias, nos rituais, nas interações e nos acontecimentos de um grupo de pessoas como um dos meios de aprendizagem dos aspetos implícitos e explícitos da sua vida rotineira e da sua cultura (DEWALT E DEWALT, 2002). Essa prática metodológica, de forma sistematizada e orientada para esse estudo ocorreu em algumas situações que podem ser destacadas:
1) em duas visitas na condição de turistas para observação das características dos objetos analisados;

2) em uma visita como pesquisadores de turismo, acompanhados pelo arquiteto responsável do Museu do Pão.

Este trabalho segue a abordagem sobre a segmentação da oferta turística do Ministério do Turismo (MTUR, 2007), que destaca que a segmentação é entendida como uma forma de organizar o turismo para fins de planejamento, gestão e mercado.

Sobre as classificações, a presente pesquisa, quanto aos objetivos, é exploratória e descritiva e, quanto aos procedimentos técnicos, é estudo de caso que utiliza como técnicas a observação participante, a revisão bibliográfica integrativa e a análise documental. Quanto à abordagem do problema, é qualitativa e, quanto ao método do trabalho, é dedutivo.

\section{Turismo, cultura e turismo cultural}

A constituição dos espaços de cultura e preservação do patrimônio são diversos e plurais, mas o ícone da representatividade, quase um templo da manutenção da história, cultura, tradições e manifestações culturais, reconhecido como fator da apresentação das peculiaridades de qualquer comunidade é o museu.

Para International Council of Museums (ICOM) o museu é

[...] uma instituição permanente, sem fins lucrativos, ao serviço da sociedade e do seu desenvolvimento, aberto ao público, e que adquire, conserva, estuda, comunica e expõe testemunhos materiais do homem e do seu meio ambiente, tendo em vista o estudo, a educação e a fruição (ICOM Statutes, 2001, Art. 2)

Diferenciando museu de coleção, Mendes e Carvalho $(2013$, p. 3) expõe prerrogativas precípuas ao museu, de estudos e investigações, inventário, segurança, exposição e educação. Tais fatores, é claro, somados à visitação, que reflete o pa- 
pel social do museu, em demonstrar seus acervos como iconografia da evolução e manutenção do homem e suas heranças sociais.

Refletir sobre cultura e turismo significa compreender processos sociais e culturais que não são necessariamente quantificáveis. A cultura pode ser definida como:

o conjunto de práticas, das técnicas, dos símbolos, e dos valores que se devem transmitir às novas gerações para garantir a reprodução de um estado de consciência social. [...] cultura pressupõe uma consciência grupal operosa e operante que desentranha da vida presente os planos para o futuro (BOSI, 1992 p.11).

O termo cultura, ao ser abordado é necessária cautela (BURNS, 2002), pois se for generalizado na noção de que cultura é tudo, acaba-se distanciando do seu significado mais profundo, já que o conceito de cultura possui muitos significados de acordo com o contexto analisado. Na visão do autor, a cultura engloba a interação entre as pessoas e como essas aprendem umas com as outras; traz, ainda, a ideia de que essa aprendizagem pode ser acumulada, assimilada e passada adiante através da escrita, fala, comportamento, conhecimento, valores que são adquiridos e passados entre gerações. Nesse enfoque, percebe-se que toda sociedade muda de acordo com o ambiente e a tecnologia a qual está submetida, ou seja, o conceito é dinâmico e as culturas mudam de acordo com o tempo.

Outra forma de considerar cultura diz respeito à ideia de contraposição ao que seria "natural ou genético", ou seja, tudo que se aprende, tudo que se desenvolve ao longo da existência da humanidade. Assim, o que não é obra da natureza, tudo aquilo que foi produzido por algum ser humano, não importando o seu grau de complexidade e de desenvolvimento é cultura (GARCIA CANCLINI 1982 p.9). Nesse sentido, a capacidade de falar é natural, mas a capacidade de falar o idioma português é cultural, por exemplo.

Seguindo este contexto, Gastal e Sales (2012) retratam na museografia assemelhada a Ilópolis na italianidade de Caxias do Sul a implementação disposta por objetos em "sequência lógica que fizesse sentido para todos os visitantes e não só para especialistas, produzindo um discurso museológico inteligível através da produção material ali exposta".

O turismo é uma manifestação da cultura, e esse fenômeno está relacionado às viagens, com a visita a um local diverso da residência das pessoas. As viagens não são uma novidade da nossa época, pois, desde que se formaram as primeiras sociedades, o homem começou a viajar pelos mais diversos motivos: econômicos, políticos, sociais, culturais, esportivos e científicos. Os primórdios do Turismo estão bem mais ligados a motivos econômicos, políticos e religiosos do que propriamente de lazer. O Turismo teve seu início no século VIII a.C., na Grécia, quando as pessoas viajavam para ver os jogos olímpicos (MCINTOSH et al 2002). Outros pesquisadores afirmam que os primeiros viajantes foram os fenícios, por serem os inventores da moeda e do comércio.

O Turismo não deve ser entendido somente como um fenômeno ligado a viagens, pois tem impactos econômicos, sociais e culturais relacionados tanto com os turistas, com os residentes da localidade receptora, com a relação turista-residente e com as interações que vão além do sistema econômico. A Declaração de Manila (1980) diz que no atual processo de globalização, o Turismo tem-se revelado como uma força-motriz, contribuindo para disseminar valores, novos hábitos, costumes e para aumentar a tolerância com as diferenças, para o aumento da compreensão mundial e da paz.

Ao longo das últimas décadas do século $X X, 0$ turismo buscou uma segmentação, baseada tanto em oferta como em demandas, sendo aos poucos caracterizado em diversos tipos de turismo, visando aproximar-se dos mais diversos públicos. Dentre esses segmentos, pode ser destacado o turismo cultural. $\bigcirc$ turismo cultural caracteriza-se como aquele que "compreende as atividades turísticas relacionadas à vivência do conjunto de elementos significativos do patrimônio histórico e cultural e dos eventos culturais, valorizando e promovendo os bens materiais e imateriais da cultura" (MTUR, 2007 p. 13). Esse tipo de turismo tem sido considerado a partir de um triplo enfoque: como a superação do turismo consumista e de eva- 
são, como forma de unir os povos e como meio de desenvolvimento econômico para regiões sem a oferta clássica de lazer e entretenimento (BAUDRIHAYE, 1997 p.43).

Entre a relação entre a cultura, o turismo e a inovação parte-se do pressuposto de que são elementos intrínsecos e que podem ser encarados como integrantes de um processo de valorização:

Devemos encarar a cultura como algo que vai da tradição à invenção. Temos de preservar o que de melhor criamos e construímos em história, sob pena de nos aprisionarmos num presente desfigurador. E temos que apostar no novo, porque ele é ingrediente fundamental de afirmação e transformação de nossas comunidades e do conjunto da sociedade. Esta dialética permanente entre tradição e invenção, somada à nossa abertura crítica para assimilar e recriar linguagens e informações produzidas em outros cantos do planeta, é um traço central da cultura brasileira. (FANUCCI e FERRAZ, apud FERRAZ, 2008, p. 18)

Para Horta et al (1999) os museus são espaços de memória que patrocinam a formação da educação patrimonial, envolvendo o indivíduo na leitura da formação de seu cotidiano sociocultural pela compreensão da trajetória a partir da cronologia apresentada em seus acervos.

Portanto, assim como em tantos outros museus, a historicidade demonstrada em um museu tem representatividade de manutenção da comunidade e a trajetória descendente que resistiu as intempéries do tempo alicerçar seus laços familiares e de pertencimento ao território desbravado ou herdado.

Da mesma forma que Gastal e Sales (2012 demonstram na italianidade como patrimônio da cultura caxiense, o Museu do Pão, em llópolis tem representatividade semelhante para outro território colonizado por italianos nas terras da Província de São Pedro, atualmente, Estado do Rio Grande do Sul.

\section{Museu dopão de illópolis}

O Município de llópolis está localizado na encosta superior nordeste do planalto meridional,
Região Alta do Vale do Taquari, no Rio Grande do Sul (Figura 1). Caracteriza-se como uma pacata cidade de colonização italiana com 3.985 habitantes (FEE, 2017).

Figura 1 - Localização Ilópolis, RS

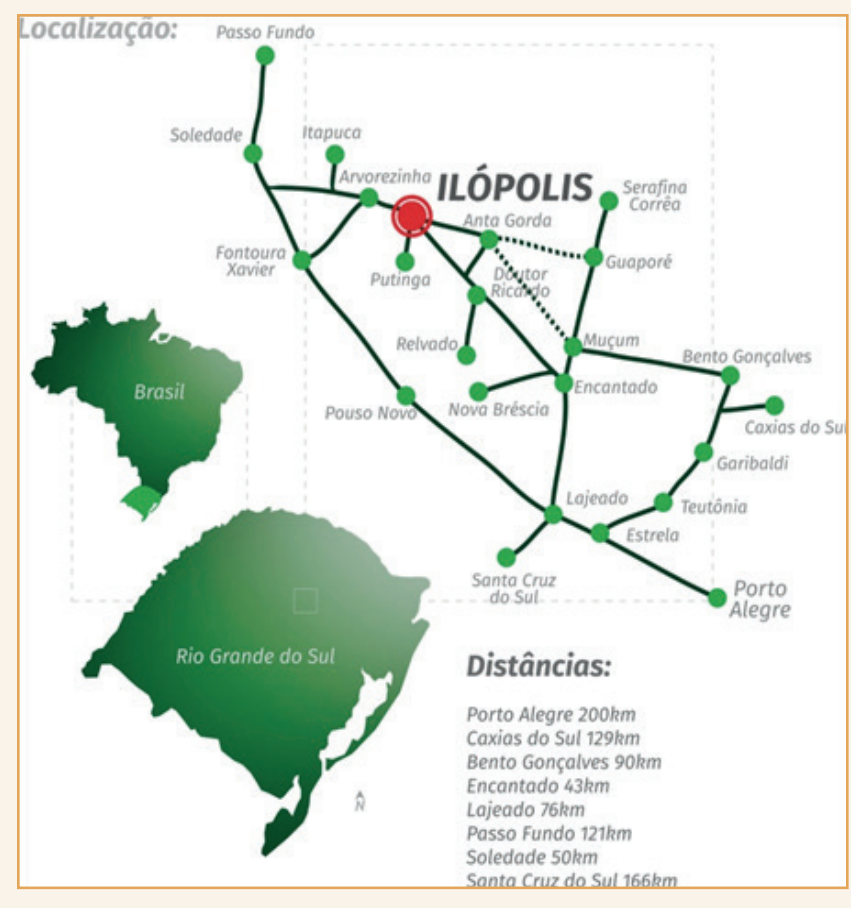

Fonte: http://www.turismate.com.br

O município emancipou-se em 1963, de Encantado - RS e sua história remete à chegada dos italianos recém chegados para ocupação das colônias vendidas aos imigrantes europeus em meados da primeira década do século passado. As tecnologias e possibilidades estavam postos à capacidade de arquitetar instrumentos e ferramentais tão quão possíveis com o que tinham, extraídos da natureza de floresta de araucária densa e ainda intocada. Mesmo em tais condições, enfrentando frio de um inverno intenso e todas as intempéries, começaram a levantar vilarejos, dentre estes o que vinha a se tornar a atual llópolis.

O tema da pesquisa remonta à chegada dos imigrantes italianos e seus conhecimentos prévios no fabrico de panifícios e a trajetória da constituição dos moinhos de farinha de trigo na região, que levou a despontar a construção de um dos mais importantes museus do Estado.

O olhar para o desenvolvimento pelo turismo tem perseguido gestores de llópolis, que é sede 
do Santuário São Paulo Apóstolo, o primeiro no mundo dedicado ao Apóstolo São Paulo.

Porém, como é uma cidade de pequeno porte, quase um vilarejo, tem somente um hotel e três restaurantes em toda cidade. Dentre os atrativos turísticos, além do frio intenso do inverno, o Lago Verde, construído artificialmente para abastecer uma pequena usina hidrelétrica já desativada, a Cascata da Baleia, formada por três quedas d'água consecutivas, que atinge uma altura de 50 metros, o Parque do Ibama, uma área de 24 hectares construído em 1957 para ser uma estação experimental de erva-mate, onde está a Trilha Ecoparque e o processo histórico da erva-mate.

Mas, o destaque é o Museu do Pão, um complexo arquitetônico que abriga museu (Figura 2), escola de panificação e o Moinho Colognese (Figura 3), construído em 1917 e ainda em funcionamento.

Figura 2 - Museu do Pão

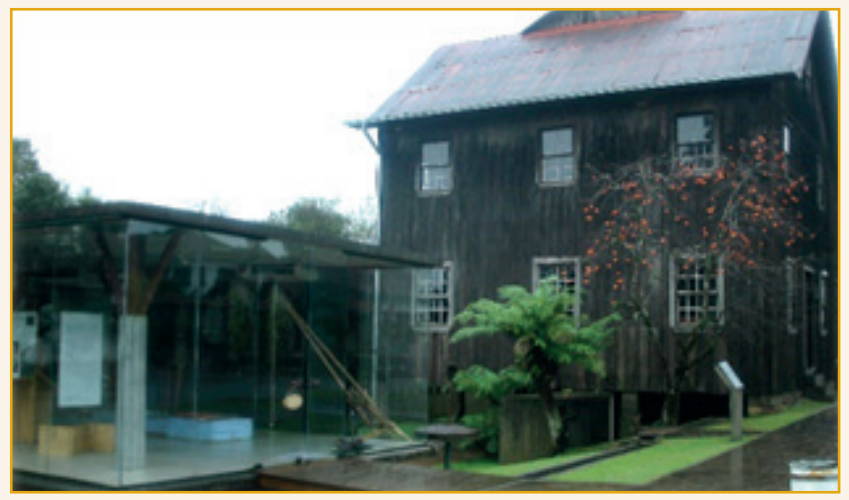

Figura 3 - Moinho Colognese

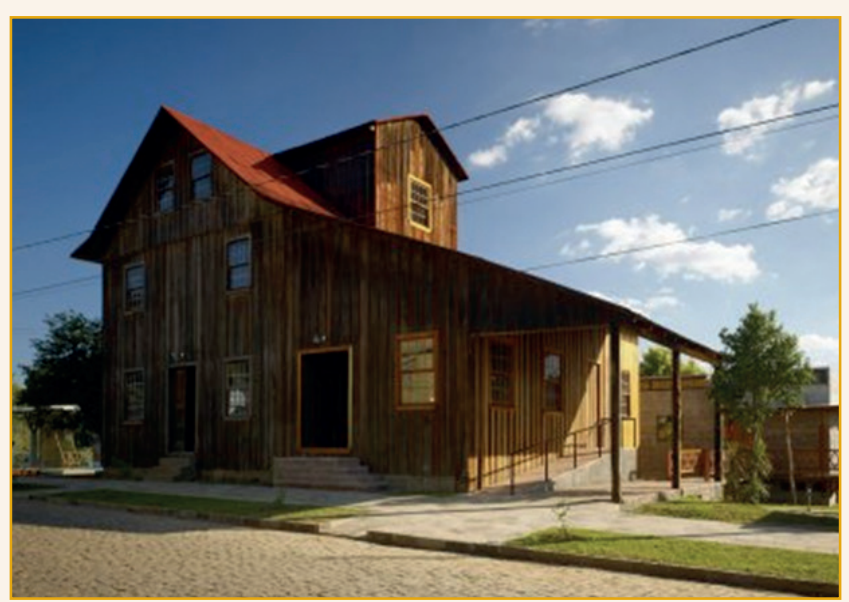

Fonte: dos autores (2014)
Na década de 1930, os irmãos Tomasini em sociedade com os irmãos Baú fundam o Moinho Tomasini e Baú, atendendo as demandas de moagem da região e consagrando-se para a produção regional. Em 1953, o prédio é vendido para os irmãos Ângelo, Savino, José, Augusto e João Ernesto Colognese e o moinho é novamente montado recebendo o nome de Colognese e Cia. Contudo, em 1976, a patente foi vendida para outro moinho, retornando para as mãos de João Ernesto Colognese em 1982.

Em 2004, é criada a Associação dos Amigos dos Moinhos do Vale do Taquari, que adquire o imóvel com recursos doados pela Nestlé Brasil para a constituição de um circuito de antigos moinhos e contar a história do pão: o Caminho dos Moinhos. O projeto inicial previu a restauração do moinho, a construção de um museu e uma oficina de panificação.

A obra foi realizada entre 2006 e 2007, patrocinada pela Nestlé Brasil, tendo apoio da Prefeitura de Ilópolis, do IPHAN e da Universidade de Caxias do Sul. O conjunto do Museu do Pão é inaugurado em 2008.

De um notável modernismo, é dialético o projeto da edificação criada ao lado do prédio do antigo moinho restaurado. No complexo (Figura 4) são oferecidas oficinas dentre as atividades da culinária tradicional e na formação e capacitação de jovens para o exercício de panificação.

Figura 4 - croqui do projeto arquitetônico do Museu do Pão

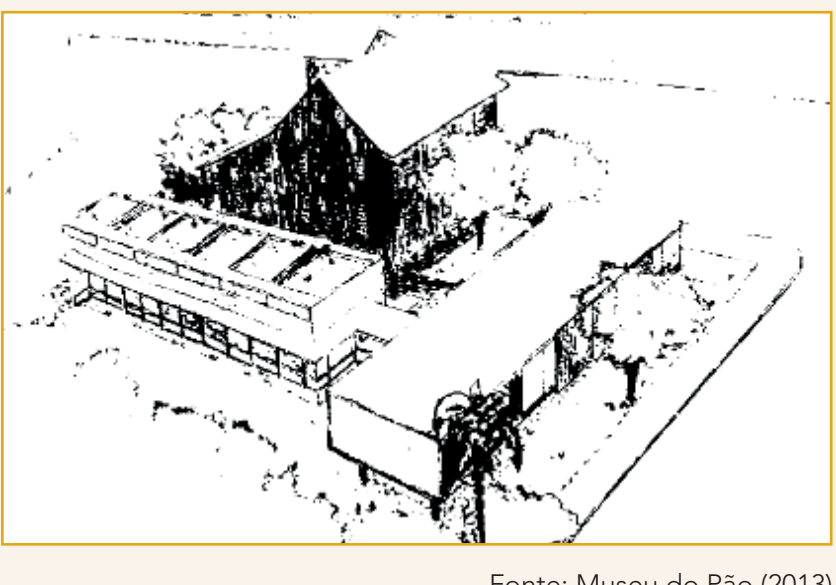

O acervo é de uma pequena coleção de ob- 
jetos utilizados pelos imigrantes italianos do Vale do Taquari que refaz a trajetória da produção do alimento "do grão ao prato". Mas, não se detém somente as peças doadas locais, pois conta na linha do tempo um resumo de 14.000 anos da presença do pão na história da humanidade. No pequeno auditório documentários, filmes e palestras elucidam temas ligados ao pão e à imigração italiana.

Manter o Complexo Arquitetônico e a manifestação social produzida assegura a dinâmica da identidade e da diversidade cultural da comunidade. No complexo as informações criam o pertencimento e identidade do indivíduo e sua cidade, onde há a possibilidade da interação de visitantes com a história pelo viés gastronômico, nas oficinas da Escola de Panificação, ou pelas recordações despertadas num passeio pelo belo Moinho.

É sedutor a quem aprecia a beleza da história representada, contada em versões que assumam o objeto foco de cada museu, em paralelo às interpretações da história contada em atividades que deem condições aos visitantes interagirem, como nas oficinas de confecção de pão. Não são apenas oficinas de culinária, mas de preenchimento cultural aos que ali se aventuram e saem satisfeitos de cumprir com o papel interativo do saber-fazer.

Nessa intervenção arquitetônico/museológica, tudo se tornou objeto expositivo: a estrutura dos edifícios, os fechamentos, o controle de luz, os passadiços, os materiais empregados, os nichos para exposição, as peças expostas. Trata do pão na história da humanidade, em uma linha do tempo - e da história do pão no "Vêneto brasileiro" do Vale do Taquari.

O Complexo Arquitetônico do Museu do Pão foi tombado na esfera municipal, para homenagear as marcas da história dos descendentes que colonizaram Ilópolis.Atualmente, o Complexo se mantém com recursos repassados pelo poder público, sendo administrado pela Associação Amigo dos Moinhos.A proteção do patrimônio cultural tem importância estratégica e simbólica na estruturação e compreensão do espaço e de suas formas de ocupação.Portanto, é imprescindível trabalhar para a identificação, promoção de bens culturais representativos da memória da cidade.

O benefício não se restringe à memória local. O Complexo Arquitetônico, tendo o Museu do Pão como destaque, pode ser considerado como o principal produto turístico do Município atraindo a atenção de visitantes para toda região. E é amplamente visitado. $\bigcirc$ homem ao reencontrar o passado toma consciência de si e dos outros, com reflexões sobre o cotidiano e se inteira da sua real condição humana, vivendo em sociedade. Quando se alia os bens patrimoniais ao turismo possibilita-se a expansão da cultura de um bem seja ele móvel ou imóvel, cultura e social (FERRAZ, 2008). Este Complexo Arquitetônico Museu do Pão, é modelo a esta referência.

A restauração do Moinho Colognese representa a lume desta história acesa nos olhos e na memória de toda uma geração. O Museu do Pão agregado a uma edificação moderna conta a história do pão através de objetos, memórias fotográficas, documentos e lendas, suas festividades e todo misticismo que rodeia esse alimento.

Até mesmo Stálin, Lênin e Kalinin se fazem representar no museu. Em outubro de 1917 eclodiu em São Petersburgo, Rússia, a Revolução Comunista comandada pelo Partido Bolchevique de Lênin. O lema era "pão, paz e terra". Tal fato faz parte da história contada do pão, em Ilópolis.

Também faz parte de seu acervo, o pão no judaísmo, o pão no cristianismo, o pão no islamismo, o pão na festa do divino espírito santo como etapas da história do pão na linha do tempo, exibido na visitação também por um documentário contando a história do pão no cine moinho, o qual faz os espectadores embarcarem numa viagem cultural inigualável. Ainda, a exposição "Do Grão ao Prato" (Figuras 5 e 6), refaz a trajetória da produção do pão por meio de uma linha do tempo que resume 14.000 anos da presença deste alimento na história da humanidade.

No Museu, são realizadas além das exposições, oficinas de panificação através das quais são oferecidos cursos periódicos em um espaço munido de equipamentos modernos e sofisticados, qualificando pessoas que podem desfrutar deste ambiente acolhedor e lúdico. Segundo (ROMA- 
NINI e SCHRAMM, 2012) as oficinas representam o "coração vivo do museu". Segundo os arquitetos, o tema se insere no resgate da culinária tradicional e na formação e capacitação por meio de cursos de panificação e confeitaria para crianças, jovens universitários e moradores da região, ministrados por pessoas especializadas na área de farináceos.

Figura 5 - Exposição do Grão ao Prato

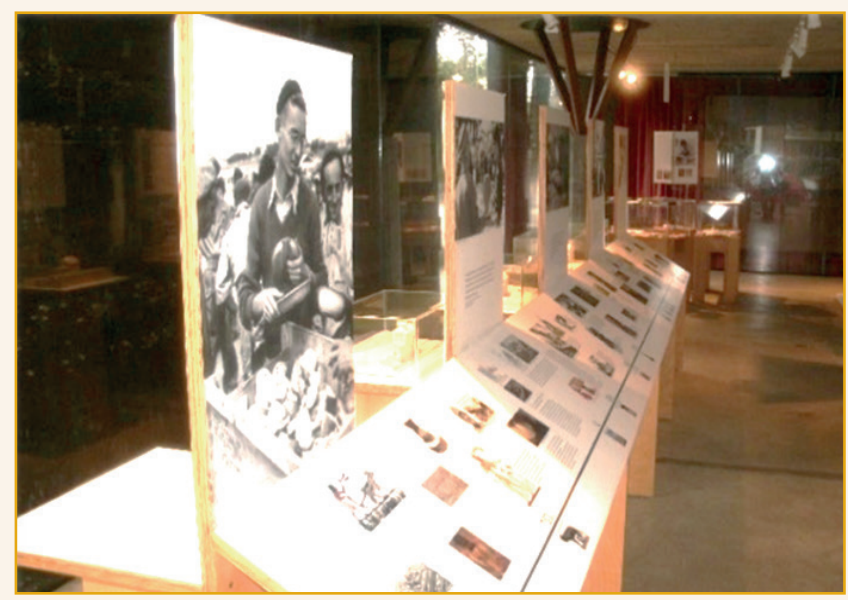

Figura 6 - Exposição do Grão ao Prato

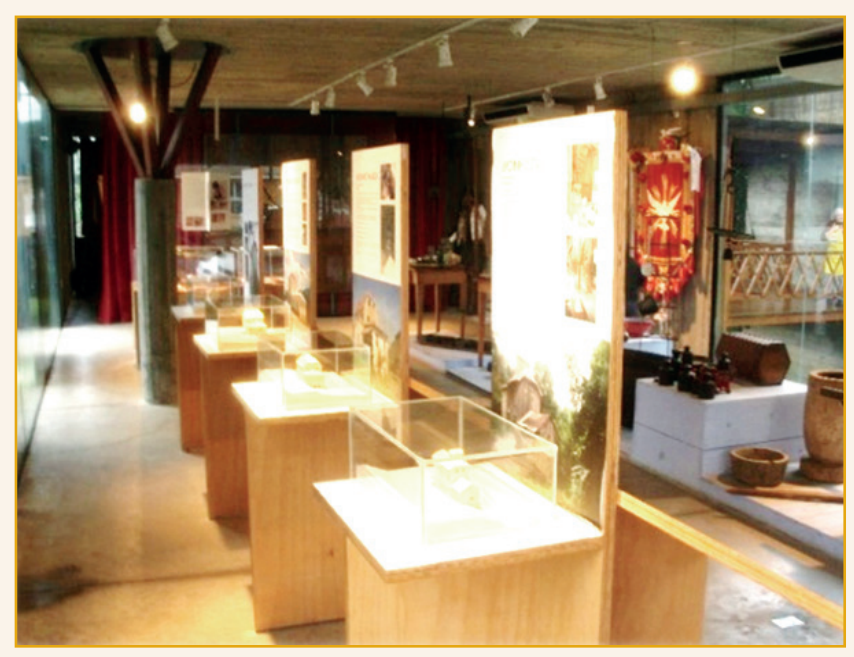

Fonte: dos autores (2014)

Detalhar as atividades de museu, transparece um momento de assumir o passado para o qual se identifica, mas não quer voltar. $\bigcirc$ agradecimento pelas conquistas dos ancestrais em consonância a oportunidade do legado aos herdeiros para novos avanços que os façam orgulhosos de uma história contada cotidianamente pelo acúmulo cultu- ral, pelos esforços do trabalho e pelas tecnologias criadas, adotadas e renovadas.

Eis, então, que surge a oportunidade de manter na história, pela educação patrimonial o reconhecimento latente desses usos e costumes antepassados. As vidas são contadas em espaços de memórias e com tantos usos diários de novas tecnologias, dinâmicas, estressantes e emocionantes, que impera compreender o público que visita para entender, admirar e se deixar seduzir pelo que observa, que toca e interage.

Dessa forma, os museus precisam se recriar constantemente num processo dinâmico de entender que quão mais moderno sejam, ora pelas peças que expõe, ora pela função lúdica que representam numa sociedade em constante transformação cultural.

Com a sua história reiniciada em 2008, o Museu do Pão, que compreende o Museu, a Oficina de Panificação e o Moinho Colognese foi considerado ponto de partida para a implantação de um produto turístico cultural: o Caminho dos Moinhos. Assume assim o papel de descrever as vivências passadas sem deixar de dialogar com o novo.

A concepção arquitetônica do museu traz esses signos, que Funari (2001, p. 25), identifica nos monumentos históricos e nos restos arqueológicos como importantes portadores de mensagens e, por sua própria natureza como cultura material, usados pelos atores sociais para produzir significado, em especial ao materializar conceitos como identidade nacional e diferença étnica, pautas latentes do museu ilopolitano.

\section{O caminho dos moinhos}

A partir do conceito desenvolvido no Museu do Pão, surge a proposta de operação mais ampla, de alcance regional: o Caminho dos Moinhos, um roteiro que agrega mais cinco estabelecimentos, alguns reativados e produzindo farinha. Essa é proposta de recuperar uma série de moinhos coloniais ainda existentes na região e integrá-los como parte de um circuito turístico e cultural.

A integração dos moinhos no dia-a-dia das 
comunidades dá aos mesmos, novo fôlego e novos papéis na região. O Caminho dos Moinhos, pauta-se pelo fato destes serem registros da imigração italiana do começo do século $X X$, sendo testemunhos de trabalho, pois, para as famílias recém-chegadas, significavam a conquista de uma vida autossustentável, sendo o pão e a massa bases desta perenidade.

A professora e ambientalista Judith Cortesão foi a idealizadora do processo de restauração, pesquisa e divulgação dos moinhos coloniais. Assim como ocorreu na criação do Museu do Pão, de llópolis, a ideia é não apenas restaurar os moinhos, mas prever a construção de atividades complementares junto a cada um deles. Em entrevista, a mesma posiciona que

Restaurar o Moinho Primeiro [Colognese] constitui - para o município e para toda a área do Alto do Taquari - serviço relevante, de impacto atual e permanente, tanto para maior compreensão da história econômica e cultural local junto às escolas como para a formação de um centro de perene interesse e de incentivo para o ecoturismo regional. (CORTESÃO in FERRAZ, 2008, p. 10)

O Caminho dos Moinhos é um roteiro que percorre quatro municípios: Anta Gorda, Arvorezinha, llópolis e Putinga (Figura 7).

Figura 7 - Mapa do Caminho dos Moinhos do Pão

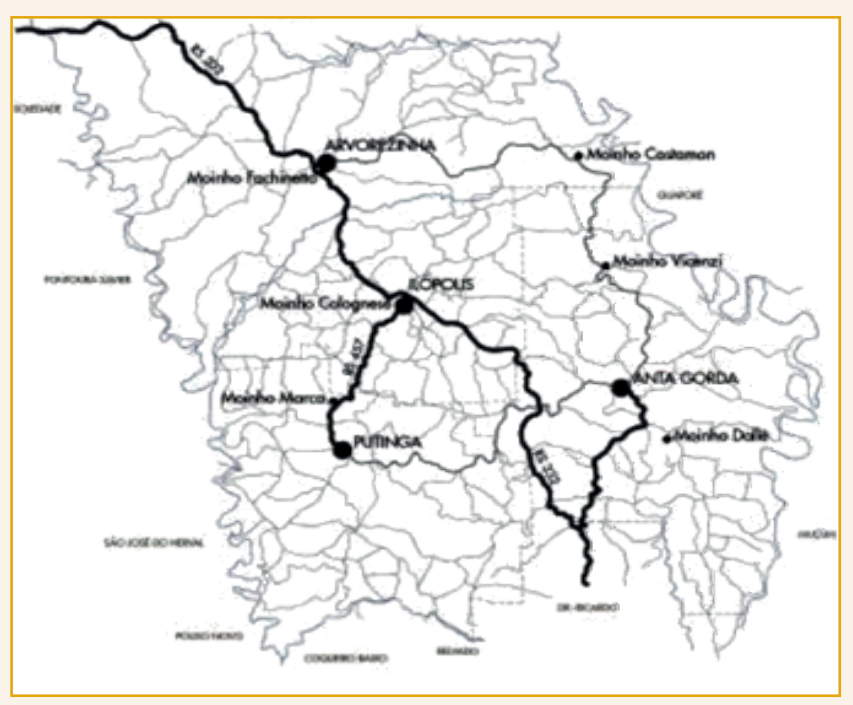

Fonte: Caminho dos Moinhos (2017)
O roteiro dos moinhos percorre uma região de belas paisagens, com vales e montanhas, rios e regatos, cachoeiras e lagos, matas de araucária, grutas, onde o ponto forte são os cinco moinhos catalogados no Quadro 1:

Quadro 1 - descrição dos Moinhos

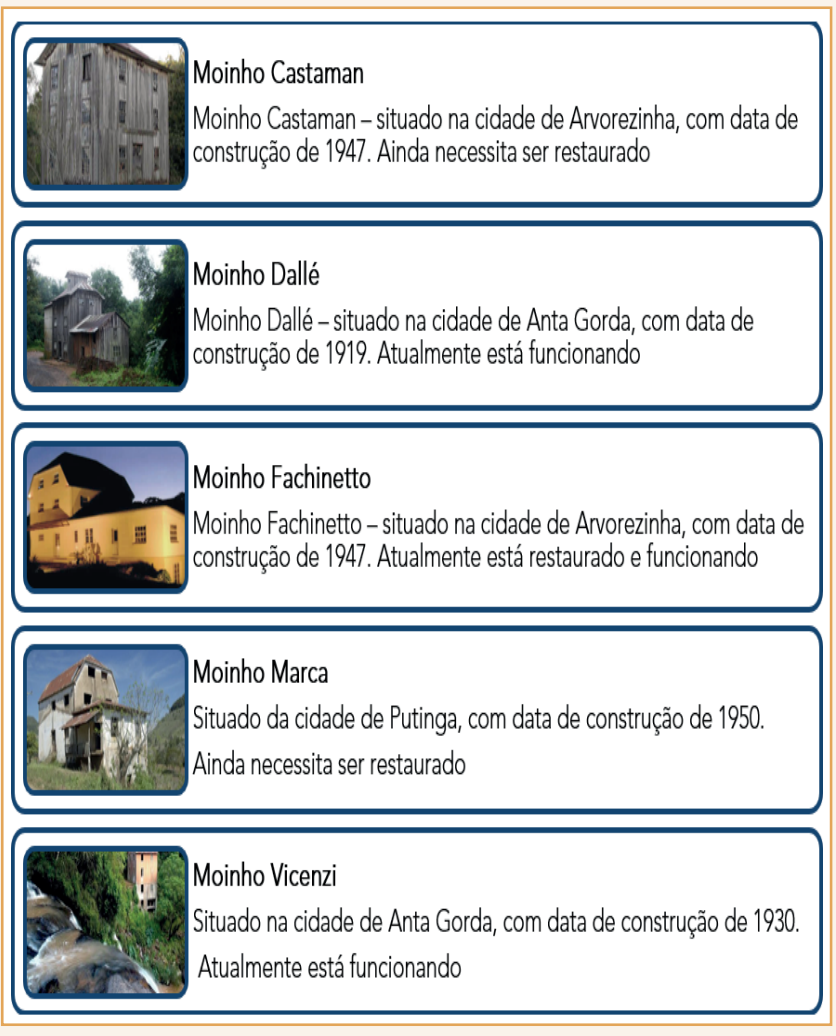

Fonte: Caminho dos Moinhos (2017)

O roteiro turístico e cultural dos moinhos leva o visitante a uma região de belíssimas paisagens: suaves vales e montanhas, rios e regatos, cachoeiras e lagos, densas matas de araucária, grutas, arquitetura rural dos imigrantes e um povo acolhedor (CAMINHO DOS MOINHOS, 2017).

Como resultado das análises realizadas propõe-se, nesse estudo alguns conceitos e indicadores, baseados em Ribeiro e Timóteo (2012), que correlacionam indicadores para entidades do terceiro setor para sua manutenção econômica que alicercem seus objetivos sociais, tal como a Associação dos Amigos dos Moinhos do Vale do Taquari, responsável pelo roteiro Caminho dos Moinhos. As proposições são apresentadas no Quadro 2: 
Quadro 2 - Categorias, definição constitutiva e indicadores de sustentabilidade

\begin{tabular}{|c|c|c|}
\hline Categorias & Conceitos & Indicadores \\
\hline \multirow{8}{*}{ Sustentabilidade Econômica } & Alocação eficiente dos recursos & Definição de Metas e Objetivos \\
\hline & \multirow{7}{*}{$\begin{array}{l}\text { Fluxo constante de } \\
\text { investimentos } \\
\text { públicos e privados }\end{array}$} & Existência de política para a qualidade \\
\hline & & Gerenciamento de riscos e crises \\
\hline & & Auditorias internas e externas \\
\hline & & Infraestrutura adequada \\
\hline & & Satisfação dos atendidos \\
\hline & & Gestão e monitoramento de processos, produtos e serviços \\
\hline & & Avaliações dos resultados da ONG \\
\hline \multirow{5}{*}{ Sustentabilidade Social } & \multirow{5}{*}{$\begin{array}{l}\text { Criação de um processo de } \\
\text { desenvolvimento sustentado } \\
\text { para uma sociedade justa pela } \\
\text { geração de emprego e renda } \\
\text { Busca da Qualidade de Vida }\end{array}$} & Geração de emprego e renda \\
\hline & & Capacitação e desenvolvimento de pessoas \\
\hline & & Programa de saúde e segurança dos desenvolvidos \\
\hline & & Sistema de trabalho socialmente aceito \\
\hline & & Integração com a sociedade \\
\hline \multirow{5}{*}{ Sustentabilidade Cultural } & \multirow{5}{*}{$\begin{array}{l}\text { Processo de desenvolvimento } \\
\text { com raízes endógenas } \\
\text { Capacidade de manter a } \\
\text { diversidade de culturas e valores }\end{array}$} & Aprendizagem organizacional \\
\hline & & Existência de código de conduta organizacional \\
\hline & & Adequação a comunicação interna e externa \\
\hline & & Imagem Organizacional \\
\hline & & Análise crítica pela organização \\
\hline
\end{tabular}

Fonte: Adaptado de Ribeiro e Timóteo (2012)

\section{Considerações finais}

O Caminho dos Moinhos precisa passar a figurar na pauta das discussões sobre o desenvolvimento turístico regional. Quanto à preservação cultural e patrimonial, deve integrar a agenda dos órgãos de desenvolvimento do turismo, em esfera regional e estadual.

A partir disso, será possível a entrada de outros empreendedores de apoio ao turismo, para que a iniciativa seja percebida pelos demais agentes sociais, principalmente para atração de investimentos que atuam no segmento de turismo, vis- to que todo caminho é composto por municípios de pequeno porte, com infraestrutura turística mínima, dependendo principalmente da infraestrutura instalada em cidades maiores, como Lajeado, onde há uma cadeia hoteleira, de alimentação e entretenimento. Neste ponto, o governo pode ser um facilitador para atração de investimentos, mas requer a acreditação empresarial no potencial de desenvolvimento proporcionado pelo Caminho dos Moinhos.

Esse potencial de desenvolvimento pode ser relacionado tanto à dimensão cultural e como à dimensão econômica que esse produto pode em- 
pregar na região. Embora a econômica esteja ligada a geração de recursos na região, de certa forma, é difícil separar os benefícios econômicos dos culturais, já que costumes e hábitos podem também ser alterados e moldados por aspectos econômicos. De forma a facilitar o argumento, em relação a dimensão econômica pode-se analisar os benefícios dos empreendimentos envolvidos na economia do turismo.

Para além da importância da dimensão econômica, é possível destacar a importância desse roteiro em termos valorização cultural. A cultura italiana, fortemente explorada na região turística da Serra, no Rio Grande do Sul, possui outros expoentes que podem complementar-se nas regiões vizinhas, sendo possível formar um conjunto de referências à cultura italiana como um todo, e que se pauta pelo resgate de autoestima local e por fim, pela preservação, reconhecimento e valorização da cultura.

Assim, o que se destaca nos motes que estabelecem os objetivos da construção desse circuito é baseado no turismo, como fator de manutenção da historicidade, da patrimonialização dos usos e costumes enraizados pelas comunidades que dominam tais técnicas. Tais fatos colaboram diretamente para o desenvolvimento local, inclusive proporcionando novos investimentos para a sustentabilidade socioeconômica, que, conforme ilustrado no Quadro 2, adaptado de Ribeiro e Timóteo (2012), que correlacionam indicadores para entidades do terceiro setor para sua manutenção econômica que alicercem seus objetivos sociais, tal como a Associação dos Amigos dos Moinhos do Vale do Taquari, responsável pelo roteiro Caminho dos Moinhos.

Tem-se assim, a perspectiva da perenidade do roteiro a partir da concepção de sucesso da própria entidade que se estrutura a partir da manutenção da herança cultural e a constituição de processos de promoção e venda de produtos representativos da educação patrimonial ofertada a partir dos moinhos da região, tendo, é claro, como âncora, o Museu do Pão.

Promover a história da valorização dos moinhos italianos representa uma relevante forma de se preservar e divulgar a origem cultural e a identidade daqueles imigrantes italianos do Alto do
Vale do Taquari que decidiram através da produção de farinha de trigo, conduzir suas vidas e constituir seus patrimônios, sejam materiais, culturais, econômicos e sociais. Os moinhos, dessa forma, representam a memória do povo italiano, a sua história econômica e social, a sua história tecnológica e, o repositório de crenças, ditos e pequenas histórias que constituem parte do imaginário popular.

O entendimento da preservação do patrimônio histórico, artístico e cultural, é um importante exponencial para o desenvolvimento da região, pois é a lembrança dos atores do passado e exerce importante papel possibilitando a transmissão às gerações futuras das referências de um tempo e de um espaço singulares (MAIA, 2003).

No caso especifico analisado, fica claro que com o passar dos anos e deparados com a proibição da produção de farinha de trigo em moinhos artesanais, os prédios foram abandonados. No entanto, com a recuperação do moinho de llópolis, a Associação dos Amigos dos Moinhos do Alto do Vale do Taquari projeta com que o Caminho dos Moinhos, partindo da restauração e revitalização do antigo Colognese e da constituição do Museu do Pão, converter-se-á em um produto turístico que caiba nas prateleiras de comercialização do turismo das melhores agências de turismo do país.

O moinho se apresenta como o primeiro passo para construção de um acervo, rico e interminável sobe a constituição do pão, como item fabril que o homem o concebe em todos os recantos que compõe o nosso mundo e abre inovações às tecnologias instaladas na região desde os meados do século XIX no Vale do Taquari.

Vale difundir também que o direito à memória será garantido quando a comunidade tomar consciência da sua função de guardiã do próprio patrimônio (MAIA, 2001), passando então a impedir a deterioração ambiental, imobiliária e mobiliária, numa ação de salvaguarda preventiva. Tal fato fundamenta não somente a obra idealizada e construída em llópolis, mas também na região a partir do Caminho dos Moinhos que tem tudo para construir o sucesso de uma empreitada que representa a história de uma sociedade.

Mas, obviamente, é necessário ampliar e me- 
Ihorar o acervo, definir melhor a estrutura e logística que atenda a todas as necessidades para visitação ao complexo e ao Caminho dos Moinhos. São questões que estarão sempre à tona, porque faz parte da construção de um patrimônio cultural. Sanados hoje, surgirão novas inquietações que levarão as mesmas perguntas e ao mesmo planeja- mento que se busca atualmente.

Cabe então, delimitar a esta pesquisa às considerações de, sem esgotar o propósito, ter revisto conceitos culturais, museológicos e patrimoniais que são fomentadores da elaboração de produtos e alavancadores da promoção socioeconômica do turismo. 


\section{Referências}

BAUDRIHAYE, Jaime-Axel. El Turismo Cultural: Luces y Sombras. Madrid: Instituto de Turismo de España Turespaña, Estúdios turísticos, 1997.

BERTO, Rosa Maria e NAKANO, Davi. A produção científica nos anais do Encontro Nacional de Engenharia de Produção: um levantamento de métodos e tipos de pesquisa. Produção, v. 9, n. 2, p. 65-76, 2000.

BOSI, Alfredo. Dialética da colonização. São Paulo: Companhia das Letras, 1992.

BOTELHO, Louise de Lira Roedel et al. O método da revisão integrativa nos estudos organizacionais, gestão e sociedade. Belo Horizonte. v. 5, n. 11, p. 121-136 maio/agosto 2011.

BRASIL ARQUITETURA. Museu do Pão, 2008. Disponível em: http://brasilarquitetura.com/projetos.php $? m n=25 \& \mathrm{img}=001 \& \mathrm{bg}=\mathrm{img} \& \mathrm{mn} 2=92 \% \mathrm{lg}=\mathrm{pt} \_$BR Acesso em 10 maio 2017.

BURNS, Peter. Antropologia do Turismo: uma introdução. Tradução Dayse Batista. São Paulo: Chronos, 2002.

CORSETI, Berenice. A análise documental no contexto da metodologia qualitativa: uma abordagem a partir da experiência de pesquisa do Programa de Pós-Graduação em Educação da Unisinos. In: UNIrevista - Vol. 1, nº 1 : 32-46 janeiro 2006

DEWALT, Ketllen e DEWALT, Billie. Participant observation: a guide for fieldworkers. Walnut, Creek, CA: Altamira Press, 2002.

FEE. Dados socioeconômicos dos municípios gaúchos. Disponível em < www.dados.fee.tche.br $>$. Acessado em 22 de maio de 2017.

FERRAZ, João Grinspum. Museu do Pão: Caminho dos Moinhos.llópolis: Associação dos Amigos dos Moinhos do Vale do Taquari, 2008.

FORZA, Cipriano. Survey research in operations management: a process based perspective. International Journal of Operations \& Production Management, v. 22, n. 2, p. 152-194, 2002.

GARCIA CANCLINI, Nestor. As culturas populares no capitalismo. Tradução Cláudio Novaes Pinto Coelho. São Paulo: Brasiliense, 1982.

GASTAL, Susana e SALES, Fabiana. Identidades sob o Turismo: a Italianidade no Sul do Brasil. Revista Iberoamericana de Turismo - RITUR, Penedo, vol. 2, n.1, p. 22-35, 2012.

GODINHO FILHO, Moacir e FERNANDES, Flávio. Um sistema para classificar e codificar os trabalhos relacionados com o Controle da Produção e o Controle da Qualidade. Gestão \& Produção, v.10, n.1, 2003.

HORTA, Maria de Loudes; GRUNBERG, Evelina; MONTEIRO, Adriana. Guia Básico de Educação Patrimonial. Brasília: IPHAN, Museu Imperial, 1999.

International Council of Museums. ICOM ANNUAL REPORT 2016. Disponível em <www.icom.museum.com >. Acessado em 17 de maio de 2017.

ILÓPOLIS, Prefeitura Municipal. História. Disponível em < www.ilópolis-rs.gov.br >. Acesso em 08 de maio de 2017.

MCINTOSH, Robert. W et al. Tourism: principles, practices, philosophies. New York: John Wilwy \& Sons, 2002 
MINISTÉRIO DO TURISMO DO BRASIL -MTUR. Marcos Conceituais da Segmentação do Turismo. Brasília: MTUR, 2007.Disponível em < www.turismo.gov.br > . Acesso em 15/07/2016.

PREFEITURA MUNICIPAL DE ILÓPOLIS. História. Disponível em < www.ilópolis-rs.gov.br>, Acesso em 08 de maio de 2017.

RIBEIRO, Lívia Maria e TIMÓTEO, Adriana. A Adoção dos Controles Internos em uma Organização do Terceiro Setor como Sustentabilidade Econômica: Um Estudo de Caso em uma Associação de Minas Gerais. In: Revista Contemporânea de Contabilidade. UFSC, Florianópolis, v.9, n.17, p.61-82, jan./jun., 2012,

ROMANINI, A. e SCHRAMM, L. Museu do Pão de llópolis: Passado e Presente em Harmonia. CATS 2012 Congresso de Arquitetura, Turismo e Sustentabilidade. Disponível em <www.catscataguases.com.br/dvd2012/ pdf /eixo3004 Museudopao ilopolis.pdf >. Acesso em 07 de maio de 2017.

TOUGUINHA, Manuel. O Patrimônio dos Moinhos do Alto do Vale do Taquari. Associação dos Amigos dos Moinhos do Vale do Taquari. S.D. Disponível em < www.caminhodosmoinhos.com.br> Acesso em 06 de maio de 2017

TURISMATE. Rota Turística Turismate. Disponível em < www.turismate.com.br >. Acesso em 07 de maio de 2017. 